Neurosurg Focus 13 (2):Article 10, 2002, Click here to return to Table of Contents

\title{
Spinal arthroplasty
}

\author{
Vincent C. Traynelis, M.D. \\ Department of Neurosurgery, The University of Iowa, Iowa City, Iowa
}

\begin{abstract}
Symptomatic degenerative spinal disease is a serious medical condition that affects many individuals. Modern neuroimaging modalities, the development of new medications, and advances in operative and nonoperative treatments have all contributed to improved outcomes. Unfortunately, there remain a significant number of patients in whom primary therapy either fails or new or recurrent symptoms develop over time. The last decade has witnessed the invention of devices designed to reconstruct the spinal motion segment. These devices can be divided into those that primarily function to replace a nucleus pulposus and those that completely replace the disc complex. In this article the author reviews the background leading to the development of the current group of disc replacements. The design and preliminary clinical results obtained using major lumbar and cervical devices are also reviewed.
\end{abstract}

\section{KeY WoRDS • degenerative disc disease • intervertebral disc • prosthesis • spinal arthroplasty $\bullet$ spinal fusion • spondylosis}

Cervical, thoracic, and lumbar spinal instrumentation led to improved outcomes in many patients in the 1980s. In the subsequent 10 years we witnessed further refinements in instrumentation, the development of new interbody techniques, improvements in spinal navigation, and an increasing focus on minimally invasive approaches and exposures. Despite these advances, there remains a genuine disparity between current and ideal patient outcomes. Presently there is tremendous interest in preservation and maintenance of both neurological and spinal function. In the future the disciplines of molecular biology and genetics may ultimately provide true regenerative capabilities. Unfortunately, this technology is in its infancy; therefore, the development of devices that preserve and/or restore the functional motion segment will constitute the next great advance in spinal surgery.

Why consider spinal arthroplasty? Current surgical strategies for symptomatic segmental spinal degeneration include decompression (usually via discectomy) and arthrodesis (with or without decompression). Each of these treatment modalities has failed to ensure large numbers of patients of long-term relief of spine-related pain.

\section{TREATMENT OF SPINAL DISEASE}

\section{Spinal Discectomy}

Many surgeons believe that the current management of simple extruded discs provides excellent results; however, this notion is not well supported by the literature. Al- though discectomy is effective in relieving significant radicular pain, its overall success rates range from 48 to $89 \% .^{9,24,40}$ In general, pain recurs in direct proportion to time from surgery. Ten years following lumbar discectomy, 50 to $60 \%$ of patients will experience significant back pain and 20 to $30 \%$ will suffer recurrent sciatica. ${ }^{29}$ In general, these suboptimal results are most likely related to continuation of the degenerative processes, recurrent disc ruptures, segmental instability, and spinal stenosis. ${ }^{28,29}$

There are numerous reasons for the failure of surgical therapy. In some patients disc degeneration may not have been the primary pain generator. Other relapses may be due to disc space collapse. Although disc height is often decreased preoperatively in patients with a herniated nucleus pulposus, it is even more common following discectomy. ${ }^{24}$ Disc space narrowing decreases the size of the neural foramina, alters facet loading and function, and may adversely affect global sagittal balance. Diminutions in the height of the disc increase intraarticular pressure, thereby producing abnormal loading patterns, which may lead to biochemical changes in the intraarticular cartilage at both the level of the affected disc and the adjacent level. ${ }^{14,22}$ Overall, this process predisposes individuals to develop hypertrophic changes of the articular processes. ${ }^{44}$ Furthermore, segmental narrowing allows for rostral and anterior displacement of the superior facet joint, which becomes very important when it impinges on the exiting nerve root that traverses an already compromised foramen. ${ }^{30}$

Another source of continued pain is destabilization of 
the functional spinal unit. The stiffness of a segment is inversely related to the amount of nuclear material that is removed. Even partial disc excisions are associated with significant increases in sagittal, coronal, and axial rotation across the affected segment. ${ }^{19}$ Disc excision may also lead to instability at the level above the surgically treated segment. ${ }^{20,47,48}$

\section{Spinal Arthrodesis}

Arthrodesis, with or without decompression, has been a major surgical treatment for symptomatic spinal spondylosis for more than 40 years. ${ }^{6-8,35,46}$ Fusion eliminates segmental instability, preserves sagittal balance, and halts further degeneration at the surgically treated level(s). Additionally, interbody procedures can be performed to restore normal disc space height. The major rationale for spinal arthrodesis is that pain can be relieved by eliminating motion across a destabilized or degenerated segment. ${ }^{51}$ Good to excellent results have been reported in 52 to $100 \%$ of patients undergoing anterior lumbar interbody fusions and 50 to $95 \%$ of those undergoing posterior lumbar interbody fusion. ${ }^{31,42,50,56,57}$

Spinal fusion is not, however, a benign treatment. Numerous patients may develop recurrent symptoms years after the original procedure. Lehmann, et al., ${ }^{32}$ assessed the long-term (21-33-year) results of lumbar fusions. They found that approximately $50 \%$ of patients suffered lowback pain requiring medication at last follow up and approximately $15 \%$ required additional surgery during the study period. Fusion perturbs the biomechanics of adjacent vertebral levels, which may be the reason that symptomatic hypertrophic facet arthropathy, spinal stenosis, disc degeneration, and osteophyte formation have all occurred at levels adjacent to a fusion site. . $18,25,28,32,34,49$ Finally, there are a number of other drawbacks to fusion, including loss of spinal mobility, graft collapse resulting in suboptimal sagittal balance, autograft harvest site pain, and alteration of muscular synergy. Even in the cervical spine, where the results are thought to be better than in the lumbar region, Hilibrand and coworkers ${ }^{26,27}$ have reported that the rate of symptomatic disc degeneration in levels adjacent to a cervical fusion is approximately $3 \%$ per year. DiAngelo, et al., ${ }^{12}$ have demonstrated that arthrodesis increases local motion in adjacent segments as well as their contribution to global cervical motion. This is probably a significant factor in the acceleration of adjacent-level disc degeneration.

Adequate neural decompression will eliminate radiculopathy and halt progression of myelopathy in almost all cases. The primary cause of recurrent radicular and persistent or recurrent axial pain following surgical treatment of degenerative disc disease is almost certainly inadequate or nonphysiological reconstruction of the spinal column. Just as hip and knee arthroplasty revolutionized the treatment of degenerative disease in these joints, it is possible that the development of the artificial disc may similarly affect the treatment of spinal spondylosis.

The idea of replacing a spinal disc is not new. One of the first attempts to perform disc arthroplasty was undertaken by Nachemson ${ }^{39} 40$ years ago. Fernstrom ${ }^{17}$ attempted to reconstruct intervertebral discs by implanting stainless-steel balls in the disc space. In 1966 he reported on
191 implanted prostheses in 125 patients. Subsidence occurred in $88 \%$ of patients during the 4- to 7 -year follow-up period. These pioneering efforts were followed by more than a decade of research on the degenerative processes of the spine, spinal biomechanics, and biomaterials before serious efforts to produce a prosthetic disc resumed.

\section{SPINAL ARTHROPLASTY}

There are a number of factors that must be considered in the design and implantation of an effective disc prosthesis. The device must maintain the proper intervertebral spacing, allow for motion, and provide stability. Natural discs also act as shock absorbers, and this may be an important quality to incorporate into prosthetic disc design, particularly when considered for multilevel lumbar reconstruction. Currently, spinal segmental reconstruction can be divided into two groups: nucleus replacement and total-disc replacement.

\section{Nucleus Replacement}

Replacements for the nucleus pulposus are designed to be used in cases in which the nucleus has undergone significant degeneration but the anulus and supporting fibers are relatively healthy. ${ }^{3}$ Contraindications to disc nuclear replacements include an interspace less than $5 \mathrm{~mm}$, spondylolisthesis, and Schmorl nodules, all of which may adversely affect the implant's performance.

The most widely studied nucleus replacement is the Prosthetic Disc Nucleus. At least 450 patients have been treated with this implant. This device replicates the physiological function of the nucleus and can restore disc space height. The Prosthetic Disc Nucleus implant consists of a hydrogel core constrained within a woven polyethylene jacket (Fig. 1 upper left). ${ }^{43,45}$

To minimize the preimplantation size of the Prosthetic Disc Nucleus, the hydrogel core is compressed and dehydrated during manufacturing. Platinum-iridium wire markers inserted into the core allow radiographic identification of the device. The tightly woven, ultrahigh-molecular weight polyethylene allows fluid to pass through to the hydrogel. This flexible but inelastic jacket constrains horizontal and vertical expansion upon hydration yet permits the hydrogel core to deform and reform in response to changes in compressive forces. Once implanted, the hydrogel immediately begins to absorb fluid and expand. Although most hydration occurs in the first 24 hours, the Prosthetic Disc Nucleus requires approximately 4 to 5 days to reach maximum expansion. Currently this is the only nucleus replacement that can distract the interspace. Because of its distraction capabilities, it can be implanted into segments as small as $5 \mathrm{~mm}$, whereas the nondistracting nucleus replacements will probably function best in disc spaces that have maintained a height of $10 \mathrm{~mm}$.

The Prosthetic Disc Nucleus device is available in 5-, 7-, and 9-mm sizes. There are both anterior and posterior implants that are available in rectangle or wedge-shaped configurations. Sizing templates help to determine if a patient should receive one or two implants. Placement of two Prosthetic Disc Nucleus devices within the disc 


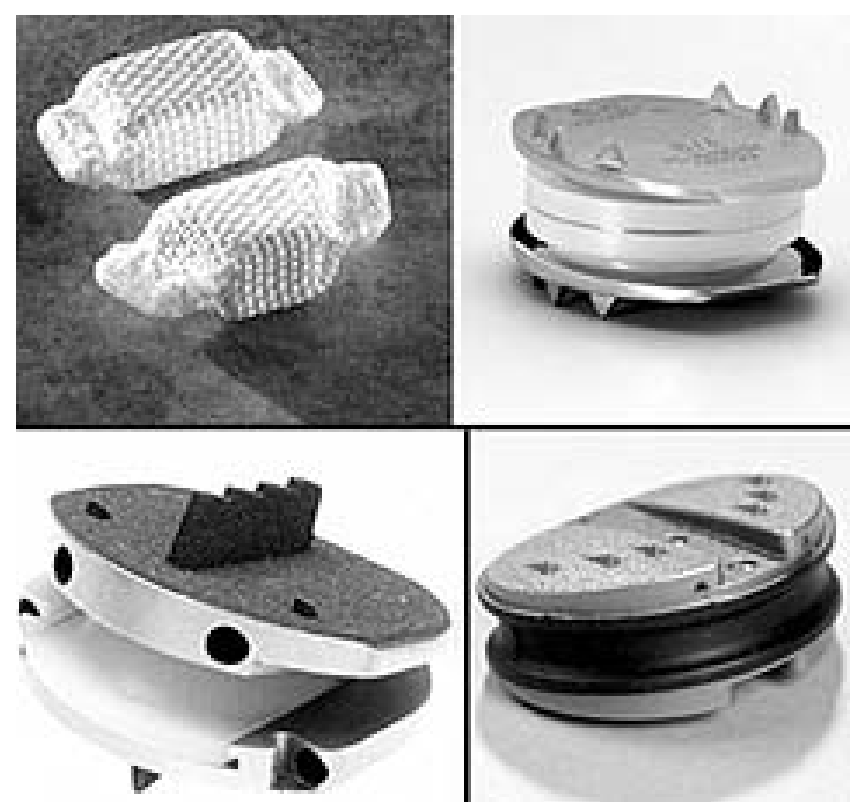

Fig. 1. Photographs demonstrating the PDN (upper left), Link SB Charité disc (upper right), Prodisc (lower left), and Acroflex Disc (lower right).

space is optimal for symmetrical elevation of the segment. When two implants are placed in a single interspace, they are tied together by using a suture to minimize the risk of migration. This device has been extensively assessed by mechanical and in vitro testing, and the results have been favorable. ${ }^{43,45}$

Wilke, et al. ${ }^{54}$ examined the biomechanics of cadaveric lumbar spines in which the Prosthetic Disc Nucleus was inserted at the L4-5 level. Six spine specimens were preloaded with $200 \mathrm{~N}$, after which sagittal, coronal, and axial rotation was assessed following exposure to a $7.5-\mathrm{Nm}$ load in each of the respective planes. The disc space height in the neutral position was also measured. The spines were examined in the intact condition, following a right unilateral hemilaminotomy and discectomy, as well as after implantation with two nonsutured Prosthetic Disc Nucleus implants. In this testing paradigm, the Prosthetic Disc Nucleus implants normalized motion kinetics in the postdiscectomy spines and increased the disc space height. This study is flawed by the fact that the Prosthetic Disc Nucleus implants were not allowed to become fully hydrated. Full hydration probably would have increased the disc space height further and may have altered the mechanical properties of the device itself.

Clinically, Schönmayr, et al., ${ }^{45}$ reported on 10 patients treated with the Prosthetic Disc Nucleus in whom a minimum of 2 years of follow-up data were available. Significant improvement was seen in both the Prolo and Oswestry Disability Index Scale scores, and segmental motion was preserved. Overall, excellent results were demonstrated in eight patients. Migration of the implant occurred in three patients, but only one required reoperation. One patient, a professional golfer, responded favorably for 4 months until his pain returned. Marked degeneration of his facets occurred, and his pain was relieved by facet injections. He underwent fusion and since has done well. Although the devices have been primarily inserted via a posterior exposure, one physician has described Prosthetic Disc Nucleus placement via an anterolateral route traversing the psoas muscles ( $\mathrm{R}$ Bertagnoli, unpublished data). One advantage of this technique is to avoid the migration that occurs in up to $8 \%$ of cases in which surgery is performed via the posterior approach. The lateral anular opening is not in the sagittal plane and does not result in iatrogenic injury to the important tension bands (anterior and posterior longitudinal ligaments). I am unaware of any Prosthetic Disc Nucleus-related migration following placement performed by traversing the psoas muscles.

A number of other nucleus replacement implants are under development. In contrast to the Prosthetic Disc Nucleus device, none of the new implants appears to be able to increase the intervertebral disc space height. No significant volume of clinical data exists concerning the outcomes of patients receiving these implants; therefore, it is impossible to make any valid assessment concerning outcomes at this time.

Aquarelle is a hydrogel-based nuclear replacement. The hydrogel material is a polyvinyl alcohol, which is hydrated to a physiological water content of approximately $80 \%$ prior to implantation. This viscoelastic material exerts a uniform pressure across the endplates. Biomechanically, the Aquarelle device has performed well in fatigue testing up to 40 million cycles. The authors of cadaveric studies have demonstrated that the device does not extrude after implantation, and there was no evidence of local or systemic toxicity to the polyvinyl alcohol or its particles in a baboon study (H Yuan, unpublished data).

Aquarelle is inserted through a 4- to 5-mm tapered cannula that enters the disc space via a small opening in the anulus. The interspace may be accessed via a lateral or posterior route.

Newcleus is a spinal nuclear replacement device constructed with a polycarbonate urethane elastomer. The material is biocompatible and has been used in cardiovascular applications. Newcleus is manufactured in a manner that aligns the molecular chains in a specific configuration, which causes the device to curl up in a spiral in its natural state. This property enables Newcleus to fill fully the intervertebral space and exert tension on the anulus. Postimplantation, the device absorbs water to approximately $35 \%$ of its net weight. Functionally, it acts as a spacer with some shock-absorbing capabilities. The device is implanted using the same approach as for microdiscectomy. It may be possible at some point to place the implant percutaneously.

At least two nuclear replacements are being developed that consist of polymers that are cured in situ. The ability to insert these implants via a small anular window may be an attractive factor in selected patients. Theoretically, this would allow for implantation in a minimally invasive procedure with very little risk of implant-related migration.

The Prosthetic Intervertebral Nucleus is an in situ curable polyurethane that is injected into a polyurethane balloon through an attached catheter. It polymerizes in the disc space in minutes, after which the catheter is removed. BioDisc is constructed with a protein hydrogel. This in situ curable protein hydrogel is injected into the disc space and cures within minutes. 


\section{C. Traynelis}

\section{Total-Disc Replacement}

The Link SB Charite III, now in its third generation, is the most widely implanted total-disc replacement. ${ }^{36}$ Overall, more than 2000 devices have been implanted worldwide. The Charité III consists of a biconvex ultrahighmolecular weight polyethylene spacer surrounded by a radiopaque ring for radiographic localization. The spacers are available in different sizes. This core spacer interfaces with two separate endplates constructed using casted CoCrMo alloy. Each endplate has ventral and dorsal teeth to discourage migration. The endplates are coated with titanium and hydroxyapatite to promote bone bonding (Fig. 1 upper right). The prosthesis is available in five different sizes: $7.5 \times 23,8.5 \times 25,9.5 \times 27,10.5 \times 29$, and $11.5 \times 31 \mathrm{~mm}$ (height $\times$ width). The endplates vary in angulation from 0 to $10^{\circ}$. The unique design of the Charité III allows it to provide unconstrained kinematic motion across the implanted spinal segment device. Although there is great concern regarding wear-related debris in hip prostheses in which ultrahigh-molecular weight polyethylene articulates with metal, this does not appear to occur when the Charité III device is used. ${ }^{36}$

To date, the overall Charité implant-related results have been good. In 1994 Griffith, et al.,23 reported significant improvements in pain, walking distance, and mobility in 93 patients at 1-year follow up. A device failure, dislocation, or migration occurred in $6.5 \%$ of patients. There were three ring deformations, and three patients required reoperation. Lemaire, et al. ${ }^{33}$ published the results after implanting the SB Charité III device in 105 patients for whom the mean follow-up period was 51 months. Although no displacement was associated with any of the implants, three of them settled. The overall outcome-related failures appeared to be due to facet pain. David ${ }^{11}$ described a cohort of 85 patients who underwent a minimum follow-up period of at least 5 years after the Charité prosthesis was implanted. Good or excellent results were recorded in $68 \%$. Fourteen patients reported the result as poor, 11 of whom underwent secondary arthrodesis at the prosthesis-implanted level. It is interesting to note that this surgeon treated 20 patients with spondylolisthesis or retrolisthesis and that the outcome was identical to that of the entire group. Clinical trials involving the Charité III prosthesis are ongoing worldwide. In the United States, the Investigational Device Exemption study enrollment has recently been completed.

The Prodisc was developed by Dr. Thierry Marnay. This implant consists of two CrCoMo alloy endplates with vertical wings (Fig. 1 lower left). The endplates are coated with a pure titanium Plasmapore surface to improve osteointegration. A monoconvex polyethylene core is inserted in the caudal endplate. Because of the monoconvex configuration of the polyethylene core, this prosthesis can be inserted with considerably less segmental distraction than that required for the Charite III device. Once the polyethylene core is firmly anchored to the caudal endplate, there are only two moveable parts, which results in a kinematic behavior that is best described as semiconstrained.

Good to excellent results have been reported in the majority of patients receiving this implant (T Marnay, unpublished data). ${ }^{37}$
The first Acroflex prosthesis consisted of a hexenebased polyolefin rubber core vulcanized to two titanium endplates. ${ }^{16}$ In contrast to the two aforementioned prostheses, transmission of motion only works if there is good osteointegration of the endplates. Biomechanically, it exhibits constrained kinematics. At 3-year follow-up examination the following outcomes were reported in six patients who received the original device: two excellent, one good, one fair, and two poor. ${ }^{16}$ One patient with a poor result developed a tear in the rubber at the junction of vulcanization. The second generation Acroflex-100 consists of an HP-100 silicone elastomer core bonded to two titanium endplates (Fig. 1 lower right). Although additional patients have undergone implantation of the Acroflex100 , their outcomes have not been published. ${ }^{15}$

\section{Cervical Arthroplasty}

At first glance, it may seem a little more difficult to justify arthroplasty in the cervical spine compared with the lumbar region. Although the current procedures do an excellent job at eliminating radiculopathy and decompressing the cervical spinal cord, every operative intervention either causes some degree of destabilization or eliminates normal motion across the affected spinal unit. There is mounting evidence that arthrodesis increases stress and, therefore, the rate of disc degeneration in the cervical spine. . $^{2,4,5,13,21,26,38,41,55}$

The results of a cervical disc prosthesis, which was originally developed in Bristol, England, have been reported. ${ }^{10}$ The second-generation Cummins disc is a ball-andtrough-type device constructed of stainless steel. It is secured to the vertebral bodies with solid screws. It allows unconstrained motion across the segment (Fig. 2). Cummins, et al., ${ }^{10}$ reported on 20 patients who were followed for a mean of 2.4 years. Patients with radiculopathy improved, and those with myelopathy either improved or their symptoms stabilized. Two screws broke, and there were two cases of minor screw backout; further surgery was not required in any of these patients. One joint was removed because it was loose, a treatment failure that was thought to be due to a manufacturing error. It should be noted that the first-generation devices were produced in a local foundry. At the time of removal, the joint was firm-

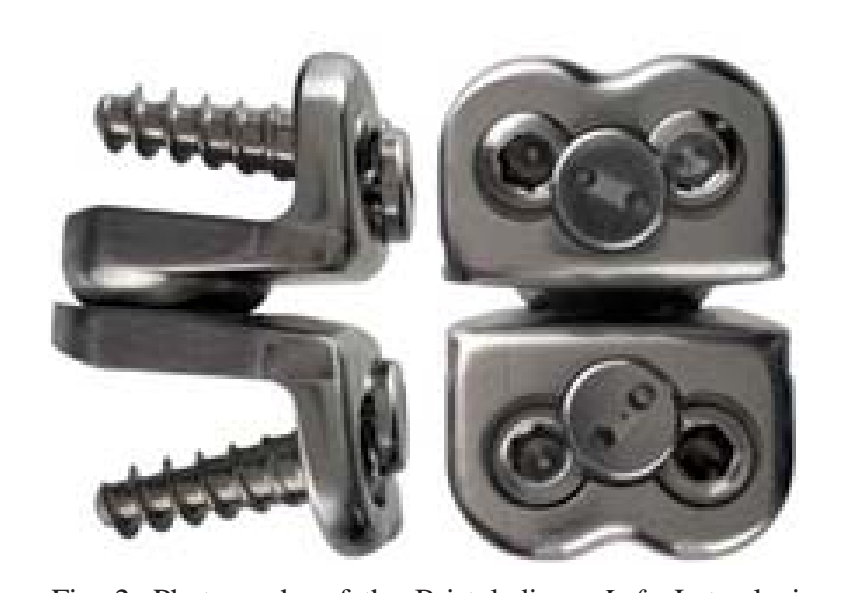

Fig. 2. Photographs of the Bristol disc. Left: Lateral view. Right: Anterior view. 
ly attached to the bone and it was covered anteriorly by a smooth scar. A detailed examination revealed that the ball-and-socket fit was asymmetrical, and it is important to note that the surrounding tissues did not contain any significant wear-related debris. Joint motion was preserved in all but two patients (Fig. 3). Both of these patients had undergone implantation of the device at the C6-7 level; the implants were so large that the facets were completely separated. This size mismatch was thought to be the reason motion was not maintained. Subsidence did not occur. The device is now manufactured in an assortment of sizes.

Wigfield and coworkers ${ }^{52,53}$ have recently reported that the Cummins/Britsol artificial disc decreases adjacent-level motion compared with an arthrodesis. This will theoretically decrease the incidence of adjacent-segment disease.

One group has presented preliminary data obtained in a prospective randomized trial in which they compared the Bristol disc with an instrumentation-assisted arthrodesis for single-level primary cervical disc disease (J Robertson, unpublished data). Analysis of the 1-year data indicated that patients in the arthroplasty arm of the study experienced greater improvement than those who had undergone arthrodesis, based on Neck Disability Index scores, both neck and arm pain visual analog scale scores, and on the mental and physical component scores of the Short Form-36. Segmental cervical motion was maintained across the surgically treated segments in all patients.

This disc prosthesis is currently being evaluated in additional clinical studies in Europe and Australia. An Investigational Device Exemption study will begin this year in the United States.

The Bryan cervical disc system is an intervertebral disc prosthesis designed to allow for normal physiological cervical motion. The device consists of a polyurethane nucleus that is situated between and articulates with two anatomically shaped titanium plates (shells) fitted to the vertebral body endplates (Fig. 4). The shells are covered with a rough porous coating to encourage osseous ingrowth. A flexible polyurethane membrane surrounds the nucleus and is secured to the endplates with a titanium wire. The closed environment prevents wear-related debris migration and also inhibits the intrusion of connective tissue. Fluid is injected into this sealed space at the time of

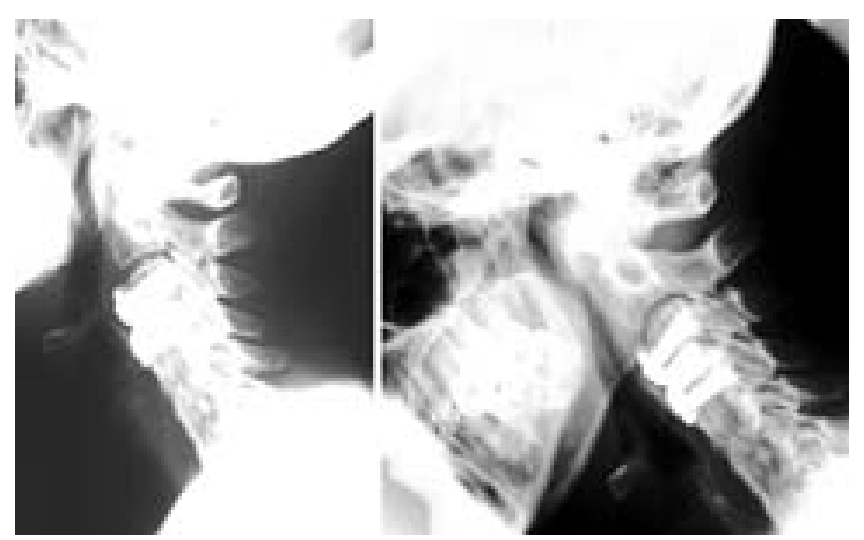

Fig. 3. Lateral cervical radiographs demonstrating the Bristol disc in extension (left) and in flexion (right).

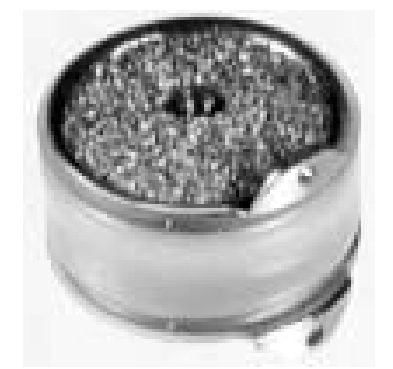

Fig. 4. Photograph showing the Bryan cervical disc.

implantation to reduce friction. The implant allows for unconstrained normal range of motion in flexion-extension, lateral bending, axial rotation, and translation. It also provides a cushioning of axial loads. The Bryan disc is manufactured in five sizes ranging from 14 to $18 \mathrm{~mm}$ in diameter.

The initial clinical experience with the Bryan Total Cervical Disc Prosthesis has been promising (Goffin, personal communication, 2000). Fifty-two devices were implanted in 51 patients by eight surgeons working at six centers in Belgium, France, Sweden, Germany, and Italy. There were no serious surgery-related or postoperative complications. At the time, 26 of the patients had been followed for 6 months, and complete clinical and radiographic data were available in 23. Excellent or good outcomes were demonstrated in $92 \%$ of the patients. Sagittal-plane rotation was maintained in all patients, and there was no significant subsidence or migration of the devices.

One group recently presented the preliminary results related to the Bryan disc when used for primary cervical spinal disc degeneration (A Casey, et al., unpublished data). The device performed well in all outcome measures tracked. There were no device-related complications, and motion was preserved.

In conclusion, there has been a tremendous burst of activity in the field of spinal arthroplasty. The primary goal of these devices will be to improve patient outcomes. As researchers strive to achieve this goal, our knowledge of spinal degenerative disease will surely increase.

\section{Sources of Equipment}

The Prosthetic Disc Nucleus is manufactured by Raymedica (Bloomington, MN). The Aquarelle is produced by Stryker Howmedica (Rutherford, NJ). Sulzer Spine-Tech (Edina, MN) is the maker of Newcleus device. The Prosthetic Intervertebral Nucleus is manufactured by Disc Dynamics (Minnetonka, MN) and the BioDisc by Cryolife (Kennesaw, GA). The Link SB Charité III implant is produced by Waldemar Link GmbH \& Co. (Hamburg, Germany). The Prodisc is made by Aesculap AG \& Co. KG. (Tuttlingen, Germany). DePuy Acromed (Raynham, MA) produces the Acroflex-100 prosthesis. The Bryan cervical disc system is manufactured by Spinal Dynamics Corp. (Seattle, WA).

\section{References}

1. Anderson CE: Spondyloschisis following spine fusion. J Bone Joint Surg (Am) 38:1142-1146, 1956 


\section{C. Traynelis}

2. Baba $H$, Furusawa $N$, Imura $S$, et al: Late radiographic findings after anterior cervical fusion for spondylotic myeloradiculopathy. Spine 18:2167-2173, 1993

3. Bao QB, Yuan HA: New technologies in spine: nucleus replacement. Spine 27:1245-1247, 2002

4. Cherubino P, Benazzo F, Borromeo U, et al: Degenerative arthritis of the adjacent spinal joints following anterior cervical spinal fusion: clinicoradiologic and statistical correlations. Ital J Orthop Traumatol 16:533-543, 1990

5. Clements DH, O'Leary PF: Anterior cervical discectomy and fusion. Spine 15:1023-1025, 1990

6. Cloward RB: The anterior approach for removal of ruptured cervical disks. J Neurosurg 15:602-617, 1958

7. Cloward RB: Treatment of acute fractures and fracture-dislocations of the cervical spine by vertebral-body fusion. A report of eleven cases. J Neurosurg 18:201-209, 1961

8. Cloward RB: The treatment of ruptured intervertebral disc by vertebral body fusion. III. Method of use of banked bone. Ann Surg 136:987-992, 1952

9. Crawshaw C, Frazer AM, Merriam WF, et al: A comparison of surgery and chemonucleolysis in the treatment of sciatica. A prospective randomized trial. Spine 9:195-198, 1984

10. Cummins BH, Robertson JT, Gill SS: Surgical experience with an implanted artificial cervical joint. J Neurosurg 88:943-948, 1998

11. David TH: Lumbar disc prosthesis: a study of 85 patients reviewed after a minimum follow-up period of five years. Rach Rev Pathol Vertebr 11: 1999 (Reference unverified)

12. DiAngelo DJ, Foley KT, Vossel KA, et al: Anterior cervical plating reverses load transfer through multilevel strut-grafts. Spine 25:783-795, 2000

13. Döhler JR, Kahn MR, Hughes SP: Instability of the cervical spine after anterior interbody fusion. A study on its incidence and clinical significance in 21 patients. Arch Orthop Trauma Surg 104:247-250, 1985

14. Dunlop RB, Adams MA, Hutton WC: Disc space narrowing and the lumbar facet joints. J Bone Joint Surg (Br) 66: 706-710, 1984

15. Enker P, Steffee AD: Total disc replacement, in Bridwell KH, DeWald RL (eds): The Textbook of Spinal Surgery, ed 2. Philadelphia: Lippincott-Raven, 1997, pp 2275-2288

16. Enker P, Steffee A, Mcmillin C, et al: Artificial disc replacement. Preliminary report with a 3-year minimum follow-up. Spine 18:1061-1070, 1993

17. Fernstrom U: Arthroplasty with intercorporal endoprothesis in herniated disc and in painful disc. Acta Chir Scand Suppl 357: 154-159, 1966

18. Frymoyer JW, Hanley EN Jr, Howe J, et al: A comparison of radiographic findings in fusion and nonfusion patients ten or more years following lumbar disc surgery. Spine 4:435-440, 1979

19. Goel VK, Goyal S, Clark C, et al: Kinematics of the whole lumbar spine. Effect of discectomy. Spine 10:543-554, 1985

20. Goel VK, Nishiyama K, Weinstein JN, et al: Mechanical properties of lumbar spinal motion segments as affected by partial disc removal. Spine 11:1008-1012, 1986

21. Goffin J, van Loon J, Van Calenbergh F, et al: Long-term results after anterior cervical fusion and osteosynthetic stabilization for fractures and/or dislocations of the cervical spine. J Spinal Disord 8:499-508, 1995

22. Gotfried Y, Bradford DS, Oegema TR Jr: Facet joint changes after chemonucleolysis-induced disc space narrowing. Spine 11:944-950, 1986

23. Griffith SL, Shelokov AP, Büttner-Janz K, et al: A multicenter retrospective study of the clinical results of the LINK SB Charité intervertebral prosthesis. The initial European experience. Spine 19:1842-1849, 1994

24. Hanley EN Jr, Shapiro DE: The development of low-back pain after excision of a lumbar disc. J Bone Joint Surg (Am) 71: 719-721, 1989

25. Harris RI, Wiley JJ: Acquired spondylolysis as a sequel to spine fusion. J Bone Joint Surg (Am) 45:1159-1170, 1963

26. Hilibrand AS, Carlson GD, Palumbo MA, et al: Radiculopathy and myelopathy at segments adjacent to the site of previous anterior cervical arthrodesis. J Bone Joint Surg (Am) 81: 519-528, 1999

27. Hilibrand AS, Yoo JU, Carlson GD, et al: The success of anterior cervical arthrodesis adjacent to a previous fusion. Spine 22:1574-1579, 1997

28. Hsu KY, Zucherman J, White A, et al: Deterioration of motion segments adjacent to lumbar spine fusions. Trans N Am Spine Soc: 1988 (Reference unverified)

29. Hutter CG: Spinal stenosis and posterior lumbar interbody fusion. Clin Orthop 193:103-114, 1985

30. Kirkaldy-Willis WH, Wedge JH, Yong-Hing K, et al: Pathology and pathogenesis of lumbar spondylosis and stenosis. Spine 3:319-328, 1978

31. Kuslich SD, Ulstrom CL, Griffith SL, et al: The Bagby and Kuslich method of lumbar interbody fusion. History, techniques, and 2-year follow-up results of a United States prospective, multicenter trial. Spine 23:1267-1279, 1998

32. Lehmann TR, Spratt KF, Tozzi JE, et al: Long-term follow-up of lower lumbar fusion patients. Spine 12:97-104, 1987

33. Lemaire JP, Skalli W, Lavaste F, et al: Intervertebral disc prosthesis. Results and prospects for the year 2000. Clin Orthop 337:64-76, 1997

34. Leong JC, Chun SY, Grange WJ, et al: Long-term results of lumbar intervertebral disc prolapse. Spine 8:793-799, 1983

35. Lin PM: Posterior lumbar interbody fusion technique: complications and pitfalls. Clin Orthop 193:90-102, 1985

36. Link HD: LINK SB Charité III intervertebral dynamic disc spacer. Rach Rev Pathol Vertebr 11: 1999 (Reference unverified)

37. Marnay T: L'arthroplastie intervertébrale lombaire. Med Orthop 25:48-55, 1991 (Reference unverified)

38. Matsunaga S, Kabayama S, Yamamoto T, et al: Strain on intervertebral discs after anterior cervical decompression and fusion. Spine 24:670-675, 1999

39. Nachemson AL: Challenge of the artificial disc, in Weinstein JN (ed): Clinical Efficacy and Outcome in the Diagnosis and Treatment of Low Back Pain. New York: Raven Press, 1992 (Reference unverified)

40. Nordby EJ: A comparison of discectomy and chemonucleolysis. Clin Orthop 200:279-283, 1985

41. Pospiech J, Stolke D, Wilke HJ, et al: Intradiscal pressure recordings in the cervical spine. Neurosurgery 44:379-385, 1999

42. Ray CD: Threaded titanium cages for lumber interbody fusions. Spine 22:667-680, 1997

43. Ray CD, Schönmayr R, Kavanagh SA, et al: Prosthetic disc nucleus implants. Riv Neuroradiol 12 (Suppl 1):157-162, 1999 (Reference unverified)

44. Schneck CD: The anatomy of lumbar spondylosis. Clin Orthop 193:20-37, 1985

45. Schönmayr R, Busch C, Lotz C, et al: Prosthetic disc nucleus implants: the Wiesbaden feasibility study. 2 years follow-up in ten patients. Riv Neuroradiol 12 (Suppl 1):163-170, 1999 (Reference unverified)

46. Smith GW, Robinson RA: The treatment of certain cervicalspine disorders by anterior removal of the intervertebral disc and interbody fusion. J Bone Joint Surg (Am) 40:607-624, 1958

47. Stokes IA, Wilder DG, Frymoyer JW, et al: 1980 Volvo award in clinical sciences. Assessment of patients with low-back pain by biplanar radiographic measurement of intervertebral motion. Spine 6:233-240, 1981 


\section{Spinal arthroplasty}

48. Tibrewal SB, Pearcy MJ, Portek I, et al: A prospective study of lumbar spinal movements before and after discectomy using biplanar radiography. Correlation of clinical and radiographic findings. Spine 10:455-460, 1985

49. Vaughan PA, Malcolm BW, Maistrelli GL: Results of L4-15 disc excision alone versus disc excision and fusion. Spine 13: 690-695, 1988

50. Watkins RG: Results of anterior interbody fusion, in White AH, Rothman RH, Ray CD (eds): Lumbar Spine Surgery: Techniques and Complications. St. Louis: CV Mosby, 1987, pp 408-432

51. White AA, Panjabi MM: Clinical Biomechanics of the Spine, ed 2. Philadelphia: JB Lippincott, 1990

52. Wigfield C, Gill S, Nelson R, et al: Influence of an artificial cervical joint compared with fusion on adjacent-level motion in the treatment of degenerative cervical disc disease. J Neurosurg 96 (Spine 1): 17-21, 2002

53. Wigfield CC, Robertson J, Metcalf N, et al: The influence of an artificial cervical joint versus fusion on adjacent level motion in the treatment of cervical disc disease. Neurosurgery 47:516, 2000
54. Wilke HJ, Kavanagh S, Neller S, et al: Effect of a prosthetic disc nucleus on the mobility and disc height of the L4-5 intervertebral disc postnucleotomy. J Neurosurg 95 (Spine 2): 208-214, 2001

55. Woesner ME, Mitts MG: The evaluation of cervical spine motion below $\mathrm{C} 2$ : a comparison of cineroentgenographic and conventional roentgenographic methods. AJR 115:148-154, 1972

56. Yuan HA, Garfin SR, Dickman CA, et al: A historical cohort study of pedicle screw fixation in thoracic, lumbar, and sacral spine fusions. Spine 19 (Suppl 20):2279S-2296S, 1994

57. Zucherman JF, Selby D, DeLong WB: Failed posterior lumbar interbody fusion, in White AH, Rothman RH, Ray CD (eds): Lumbar Spine Surgery: Techniques and Complications. St. Louis: CV Mosby, 1987, pp 296-305

Manuscript received July 8, 2002.

Accepted in final form July 12, 2002.

Address reprint requests to: Vincent C. Traynelis, M.D., The University of Iowa Hospitals and Clinics, Department of Neurosurgery, 200 Hawkins Drive, Iowa City, Iowa 52242. email: vincent-traynelis@uiowa.edu. 